Article

\title{
Pomelo Peel Modified with Citrate as a Sustainable Adsorbent for Removal of Methylene Blue from Aqueous Solution
}

\author{
Yimei Ren ${ }^{1}$, Chang Cui ${ }^{2}$ and Pengjie Wang ${ }^{1, *}$ \\ 1 Beijing Advanced Innovation Center for Food Nutrition and Human Health, College of Food Science and \\ Nutritional Engineering, China Agricultural University, 17 Qinghuadong Road, Beijing 100083, China; \\ renyimei123@cau.edu.cn \\ 2 Key Laboratory of Bio-Based Material Science and Technology of Ministry of Education, \\ Northeast Forestry University, 26 Hexing Road, Harbin 150040, China; 15114532032@163.com \\ * Correspondence: wpj1019@cau.edu.cn; Tel.: +86-10-627-36344
}

Received: 17 May 2018; Accepted: 1 June 2018; Published: 3 June 2018

\begin{abstract}
An anionic adsorbent was prepared by grafting citrate onto pomelo peel (PPL) to remove methylene blue (MB) from aqueous solution. The PPL and modified pomelo peel (MPPL) were analyzed by Fourier transform infrared spectroscopy (FTIR) and observed by scanning electron microscopy (SEM). The effects of dye concentration, contact time, and $\mathrm{pH}$ on adsorption were studied. The FTIR results confirmed that the carboxyl groups were successfully bound to cellulose molecules in PPL via modification with citrate. SEM indicated that the surface of PPL became clean and the porous structure was well maintained after modification. The adsorption capacities of MB onto PPL and MPPL were $81.7 \mathrm{mg} / \mathrm{g}$ and $199.2 \mathrm{mg} / \mathrm{g}$, respectively, thus indicating that the addition of anionic groups significantly improved the adsorption performance. The increase in the initial dye concentration and $\mathrm{pH}$ of the dye solution promoted the adsorption process. The adsorption equilibrium on MPPL required approximately $3 \mathrm{~h}$. The adsorption of MB on MPPL was well described by a pseudo-second order kinetic model and Langmuir isotherm model. The thermodynamic parameters indicated spontaneous and exothermic adsorption. This study suggests that PPL modified with citrate can be used as a sustainable adsorbent in wastewater purification.
\end{abstract}

Keywords: pomelo peel; modification; citric acid; adsorption; methylene blue

\section{Introduction}

In the past several decades, dye has been commonly used in the textile, paint, paper, food, leather, and rubber industries [1]. Owing to exponential population growth and consumer demand for fashion, dye demand is significantly increasing. Therefore, an increasing amount of dye is released into water already containing high concentrations of complex dyes, thus potentially severely polluting the environment and affecting human health. In the textile industry, approximately $20-30 \%$ of the applied dyes are released into effluent because of limited dyeing rates [2]. Therefore, dyes must be removed from wastewater before it enters water bodies.

Compared with physicochemical technologies, adsorption is a feasible and preferred method to completely remove dyes from water, because it is effective toward different types of dyes. In the adsorption process, the adsorbent plays a key role in the separation of pollutants from wastewater. In recent years, low-cost biomass adsorbents [3-5] have attracted research attention because of their renewability [6]. Examples of such materials include breadnut peel [7], rice hulls [8], willow branches [9], peanut hulls [10], rice straw [11], bagasse [12], hemp cellulose [13], orange peel [14], and other biomass wastes. The hydroxyl, phenolic, and carboxyl functional groups 
in the molecular structure of biomass wastes can become active sites for the adsorption of dye wastewater [15-17]. In many studies, the adsorption capacity of the biomass itself has been investigated in dye wastewater. Moreover, chemical modification can markedly improve the adsorption capacity of some biomass adsorbents.

Pomelo is planted in China and Southeast Asia; it belongs to the Rutaceae family [18] and is the largest citrus fruit, having a diameter of up to $30 \mathrm{~cm}$. The thick and soft peel accounts for $15 \%$ of the entire fruit. High consumption of pomelo produces large amounts of pomelo peels (PPLs), which are disposed of as waste, thus resulting in inefficient resource and land use. PPLs are a lignocellulose biomass mainly composed of cellulose, hemicellulose, and lignin. In some previous studies, PPL has been directly used as an adsorbent for purification of oil pollution [19] and dyes [20]. Other studies have focused on the properties of activated carbon from PPLs [21], including adsorption of uranyl [22], hexavalent chromium [23], and basic dyes [24]. Methylene blue (MB) is extensively used in dyeing materials such as fiber, paper, and hair. Therefore, it is a suitable candidate to demonstrate the application potential of a biomass absorbent. PPL was found to be an attractive candidate for MB adsorption from aqueous solution.

In this study, an eco-friendly and low-cost adsorbent was prepared by grafting citrate onto PPL and was used to remove MB from aqueous solution. The PPL before and after modification (MPPL) was analyzed by Fourier transform infrared spectroscopy (FTIR) and observed by scanning electron microscopy (SEM). The effects of the initial concentration, $\mathrm{pH}$ of the MB solution, and contact time on the adsorption of MB were studied. Adsorption kinetics models and isotherms models were used to describe the adsorption process. The thermodynamics of the adsorbents was also investigated.

\section{Results and Discussion}

\subsection{FTIR Analysis}

The FTIR spectra of PPL and MPPL are shown in Figure 1. Characteristic peaks of PPL in the spectrum were observed at $3329 \mathrm{~cm}^{-1}$ (-OH stretching vibrations), $2912 \mathrm{~cm}^{-1}$ (C-H stretching vibrations), $1733 \mathrm{~cm}^{-1}$ (-C=O stretching vibrations in polygalacturonic acid), $1613 \mathrm{~cm}^{-1}$ (-C=O stretching vibrations in lignin), and $1239 \mathrm{~cm}^{-1}$ (CO-OR stretching vibrations in hemicellulose), and a series of bands were observed at 1152, 1102, 1043, and $1022 \mathrm{~cm}^{-1}$, corresponding to $-\mathrm{C}-\mathrm{O}-\mathrm{C}-$ bonds in the anhydroglucose unit of the cellulose or hemicellulose molecule. The results showed that PPL contained cellulose, hemicellulose, lignin, and pectin. After modification, new peaks occurred at $1758 \mathrm{~cm}^{-1}$ and $1521 \mathrm{~cm}^{-1}$ and were attributed to the ester groups and carboxylate groups, respectively [25]. The changes indicated that carboxylic anions were successfully introduced into the PPL molecule after modification with citrate [26].

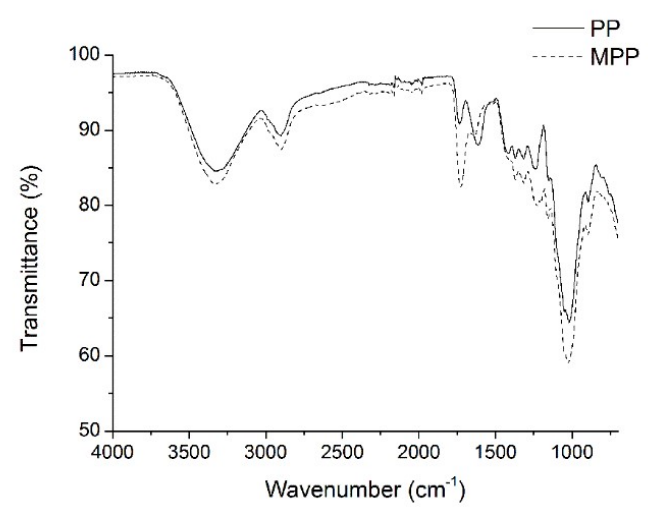

Figure 1. FTIR of the PPL and MPPL. 


\subsection{SEM Observations}

The morphology of the PPL before and after modification is shown in Figure 2. The surface of the PPL particle was rough, as shown in micrographs at low magnification. Under magnification, a porous and honeycomb-like structure was clearly seen, which is beneficial for the adsorption of dye. After modification, the porous structure was maintained, thus indicating that the initial structure of PPL was not damaged in the modification process. Moreover, the surface became cleaner after modification because some small impurities were removed in the treatment in citric acid solution.
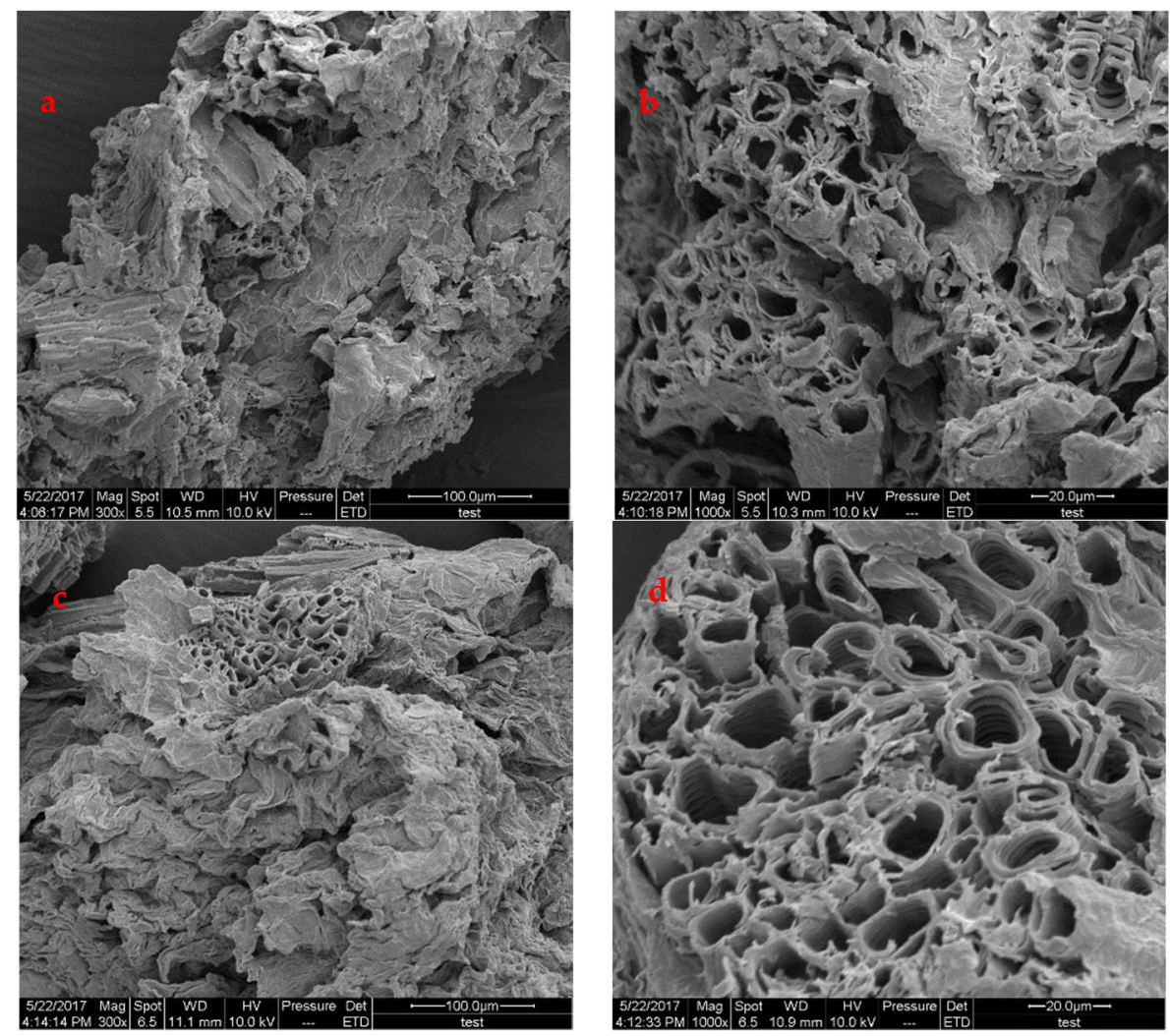

Figure 2. Surface morphology of the PPL $(\mathbf{a}, \mathbf{b})$ and MPPL $(\mathbf{c}, \mathbf{d})$.

\subsection{Comparison of $M B$ Adsorption on PPL and MPPL}

The comparison of MB adsorption on PPL before and after modification is shown in Table 1. Under the same experimental conditions, the adsorption capacities of MB on PPL and MPPL were $81.71 \mathrm{mg} / \mathrm{g}$ and $199.29 \mathrm{mg} / \mathrm{g}$, respectively. The results indicated that the modification effectively improved the adsorption performance of PPL, owing to the introduction of carboxylic anions, which interacted with cationic dye molecules via electrostatic attraction.

Table 1. Comparison of MB adsorption on PPL before and after modification.

\begin{tabular}{ccccc}
\hline Adsorbent & Dose (mg) & $\begin{array}{c}\text { MB Concentration } \\
(\mathbf{g} / \mathbf{L})\end{array}$ & $\begin{array}{c}\text { Solution Volume } \\
(\mathbf{m L})\end{array}$ & $\begin{array}{c}\text { Adsorption } \\
\text { Capacity }(\mathbf{m g} / \mathbf{g})\end{array}$ \\
\hline PPL & 10 & 50 & 50 & 81.71 \\
MPPL & 10 & 50 & 50 & 199.29 \\
\hline
\end{tabular}

\subsection{Effect of Initial Concentration on $M B$ Adsorption}

Dye concentration is a key factor affecting adsorption. Higher dye concentrations may promote absorption of more dye molecules to the active sites. The effect of initial MB concentration on the 
adsorption of MB on MPPL is shown in Figure 3. The adsorption capacity increased with increasing MB concentration. The positive correlation between $\mathrm{MB}$ concentration and adsorption capacity indicated that the absorbent did not reach saturation under the MB concentrations in the experiments.

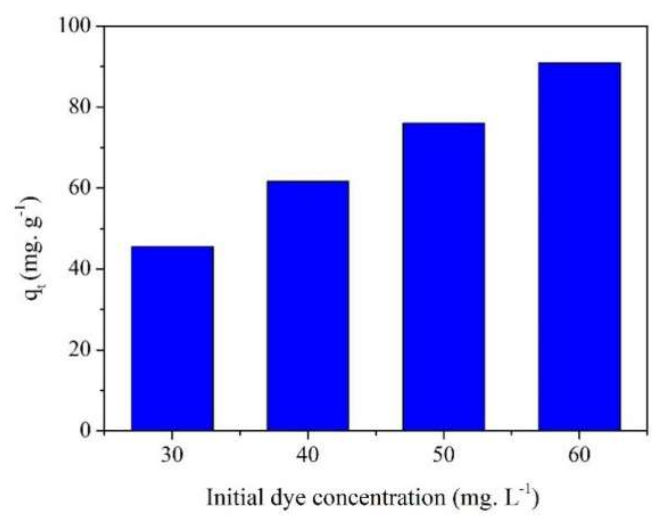

Figure 3. Effect of initial dye concentration on MB adsorption onto MPPL.

\subsection{Effect of Contact Time on MB Adsorption}

The effect of contact time on the adsorption of MB on MPPL is shown in Figure 4. The adsorption capacity significantly increased in the first $0.5 \mathrm{~h}$, and the increment of increase decreased as the contact time increased from $0.5 \mathrm{~h}$ to $2 \mathrm{~h}$ until adsorption equilibrium was reached after $3 \mathrm{~h}$. The initial high adsorption rate may have been due to the higher driving force accelerating molecules to the surface of MPPL and interacting with numerous active sites. The decrease in the adsorption rate may be attributed to the decreased number of active adsorption sites and the long-range diffusion effect of $\mathrm{MB}$ molecules. The equilibrium adsorption capacity was up to $45.4 \mathrm{mg} / \mathrm{g}$, and the removal rate was $90.7 \%$. Compared with that of the initial MB solution, the color clearly became lighter after contacting MPPL for $3 \mathrm{~h}$.

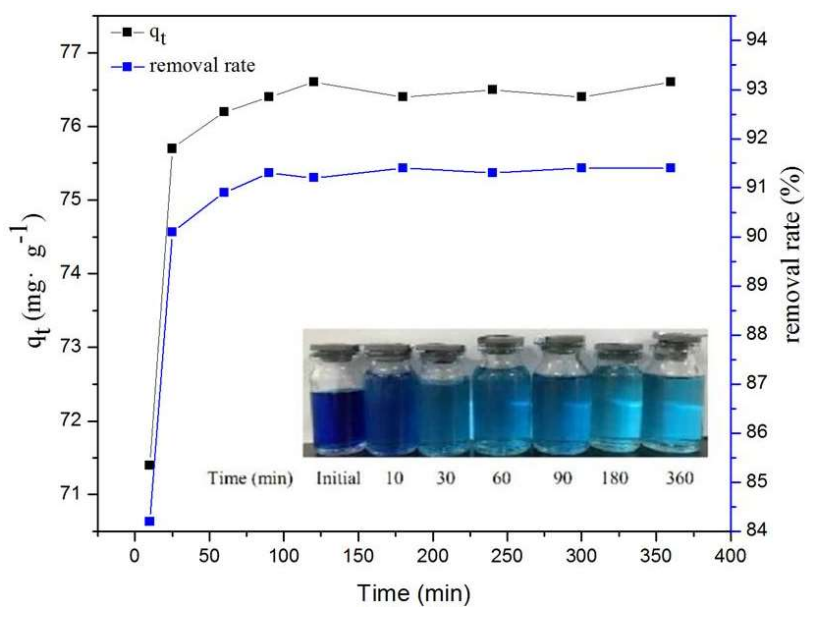

Figure 4. Effect of contact time on MB adsorption onto MPPL.

\subsection{Effect of Initial $p H$ on $M B$ Adsorption}

The effects of $\mathrm{pH}$ values on the adsorption capacity of MB on MPPL are shown in Figure 5. When the $\mathrm{pH}$ value of the $\mathrm{MB}$ solution increased from 2.57 to 4.1 , the adsorption capacity of MB onto MPPL and the removal rate of MB increased from $38.52 \mathrm{mg} / \mathrm{g}$ to $75.43 \mathrm{mg} / \mathrm{g}$ and from $46.22 \%$ to $90.51 \%$, respectively. A possible adsorption mechanism for the adsorption of MB on MPPL is shown in Figure 6. The $\mathrm{pH}_{\mathrm{PZC}}$ of MPPL was around 5.3, indicating the surface of MPPL was positively 
charged when $\mathrm{pH}<5.3$, and the MPPL presented a negative surface when $\mathrm{pH}>5$.3. At lower $\mathrm{pH}$ values $(\mathrm{pH}<5.3)$, some of the $-\mathrm{COO}^{-}$groups transformed into $-\mathrm{COOH}$ groups, which decrease the electrostatic attraction between the $-\mathrm{N}^{+}\left(\mathrm{CH}_{3}\right)_{2} \mathrm{Cl}^{-}$groups in $\mathrm{MB}$ molecules and the $-\mathrm{COO}^{-}$groups on MPPL [27]. With increasing $\mathrm{pH}(\mathrm{pH}>5.3)$, the adsorption mechanism was mainly controlled by the electrostatic attraction, thus increasing the adsorption capacity because of the higher negative charge on the MPPL surface. In theory, competition of excess $\mathrm{OH}^{-}$ions with the $-\mathrm{COO}^{-}$groups would decrease the adsorption. However, the competition from the $\mathrm{OH}^{-}$ions could decrease the electrostatic attraction between MB molecules and MPPL. Therefore, the adsorption capacity changed slightly when the $\mathrm{pH}$ was in the range of 8-10. The inset photograph shows that the solution became almost colorless at $\mathrm{pH} 10$, thus indicating that high $\mathrm{pH}$ favored the adsorption of MB on MPPL. The results showed that MPPL is an effective adsorbent for removal of MB from solutions.

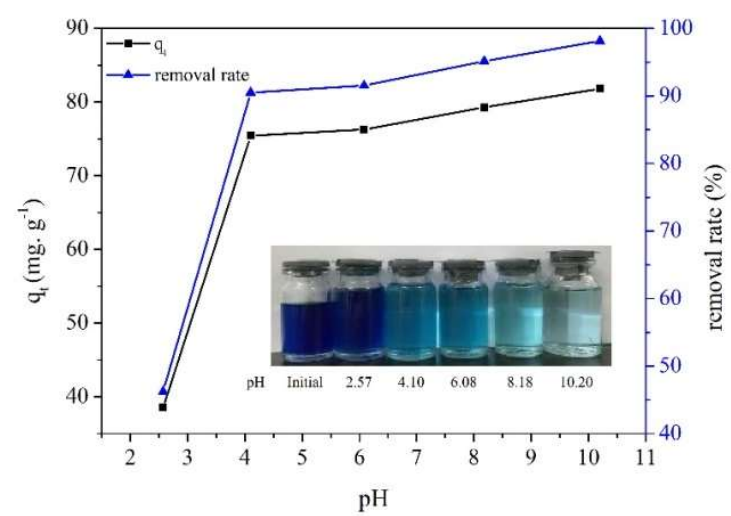

Figure 5. Effect of $\mathrm{pH}$ on $\mathrm{MB}$ adsorption onto MPPL.

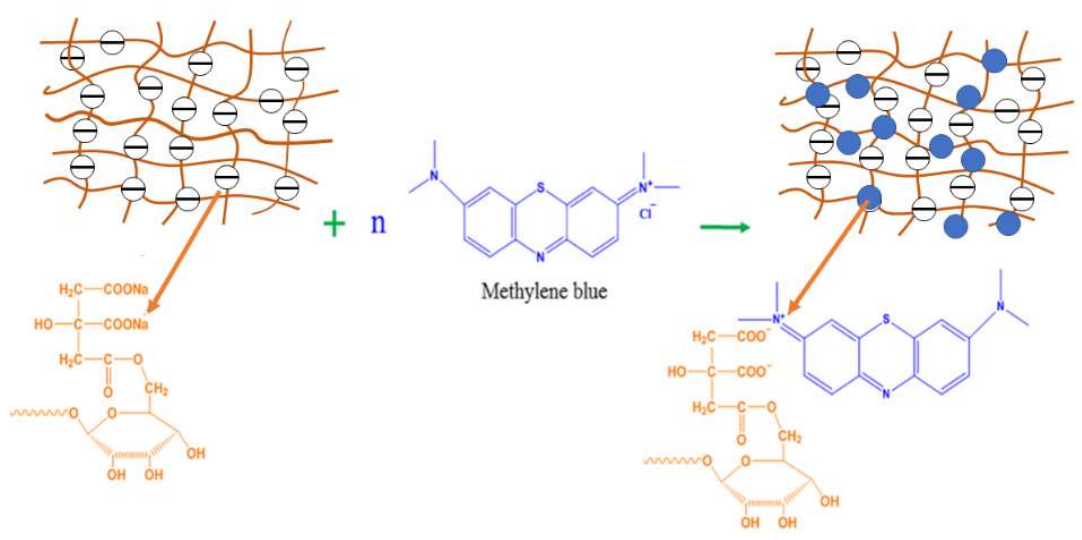

Figure 6. Possible adsorption mechanism for the adsorption of MB on MPPL.

\subsection{Adsorption Kinetics}

In the adsorption process, the behavior was determined by the spread of the adsorbate to the adsorbent and by the adsorption rate of the adsorbate on the surface of the adsorbent. Two kinetic models are commonly used to describe the adsorption behavior of dye molecules from aqueous solution on to the adsorbent: pseudo-first order and pseudo-second order kinetic models.

The pseudo-first order kinetic model [28] can be expressed as follows:

$$
\ln \left(q_{e}-q_{t}\right)=\ln q_{e}-k_{1} t
$$

where $\mathrm{q}_{\mathrm{e}}$ and $\mathrm{q}_{\mathrm{t}}$ are the adsorption capacity $(\mathrm{mg} / \mathrm{g})$ at equilibrium and time $\mathrm{t}$, respectively, and $\mathrm{k}_{1}$ is the rate constant $\left(\mathrm{L} \mathrm{min}^{-1}\right)$ of the pseudo-first order kinetic model. 
The pseudo-second order kinetic model [29] can be expressed as:

$$
\mathrm{t} / \mathrm{q}_{\mathrm{t}}=1 / \mathrm{k}_{2} \mathrm{qe}^{2}+\mathrm{t} / \mathrm{q}_{\mathrm{e}}
$$

where $\mathrm{k}_{2}\left(\mathrm{~g} \mathrm{mg}^{-1} \mathrm{~min}^{-1}\right)$ is the rate constant for the pseudo-second order kinetic model. The $\mathrm{q}_{\mathrm{e}}$ and $k_{2}$ values were obtained from the slope $\left(1 / q_{e}\right)$ and intercept $\left(1 / k_{2} q_{e}{ }^{2}\right)$ of a linear plot of $t / q_{t}$ versus $t$ at different contact times.

The plots and parameters of kinetic model for MPPL are shown in Figure 7 and Table 2. The correlation coefficients $\left(\mathrm{R}^{2}\right)$ of the pseudo-second order model were more uniform and higher than those of the pseudo-first order model. Moreover, the calculated adsorption capacity ( $q^{\mathrm{e}}$ calculated) from the pseudo-second order model was closer to the experimental adsorption capacity ( $q^{\mathrm{e}}$ experimental). The results suggested that the adsorption of MB on MPPL fitted the pseudo-second order model better than the pseudo-first-order model. This indicated that the rate of adsorption process was controlled by chemical process.
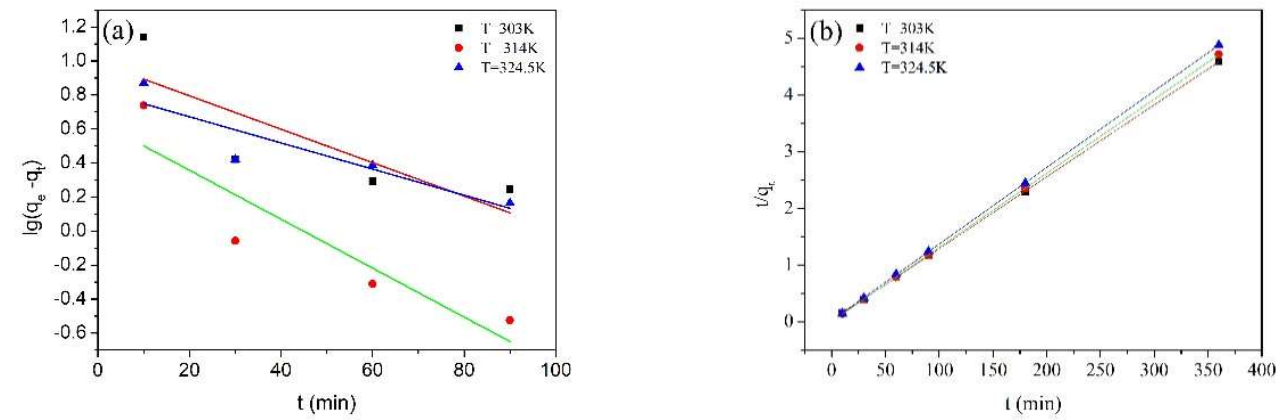

Figure 7. Pseudo-first-order (a) and pseudo-second order (b) kinetic models of adsorption of MB onto MPPL.

Table 2. Kinetic parameters for MB dye adsorption onto MPPL.

\begin{tabular}{cccc}
\hline Temperature (K) & $\mathbf{3 0 3}$ & $\mathbf{3 1 4}$ & $\mathbf{3 2 4 . 5}$ \\
\hline $\begin{array}{c}\text { qe experimental }(\mathrm{mg} / \mathrm{g}) \\
\text { pseudo-first-order model }\end{array}$ & 78.45 & 76.50 & 73.76 \\
$\mathrm{k}_{1}(1 / \mathrm{min})$ & & & \\
$\mathrm{q}_{\mathrm{e}}$ calculated $(\mathrm{mg} / \mathrm{g})$ & 0.029 & 0.016 & 0.009 \\
$\mathrm{R}^{2}$ & 1.64 & 2.31 & 2.36 \\
pseudo-second-order model & 0.9747 & 0.9913 & 0.9255 \\
$\mathrm{k}_{2}$ (mg/(g・min)) & 0.014 & 0.019 & 0.018 \\
$\mathrm{q}_{\mathrm{e}}$ calculated $(\mathrm{mg} / \mathrm{g})$ & 78.74 & 76.34 & 74.07 \\
$\mathrm{R}^{2}$ & 1.0000 & 1.0000 & 0.9999 \\
\hline
\end{tabular}

\subsection{Adsorption Isotherms}

The Langmuir and Freundlich isotherms are the most often-used isotherm models. The Langmuir isotherm is based on the hypothesis that uptake occurs on a homogeneous surface through monolayer adsorption without interaction between the absorbed molecules [30].

$$
\mathrm{C}_{\mathrm{e}} / \mathrm{q}_{\mathrm{e}}=1 /(\mathrm{bq})+\mathrm{C}_{\mathrm{e}} / \mathrm{q}_{\mathrm{m}}
$$

where $\mathrm{q}_{\mathrm{e}}\left(\mathrm{mg} \mathrm{g}^{-1}\right)$ is the equilibrium adsorption capacity of the sorbent; $\mathrm{C}_{\mathrm{e}}\left(\mathrm{mg} \mathrm{L}^{-1}\right)$ is the equilibrium concentration of the dye solution absorbed; $\mathrm{qm}\left(\mathrm{mg} \mathrm{g}^{-1}\right)$ is the maximum monolayer capacity of the sorbent; and $\mathrm{b}\left(\mathrm{L} \mathrm{mg}^{-1}\right)$ is the Langmuir isotherm constant. 
The essential characteristic of the Langmuir isotherm can be represented by the equilibrium parameter, $\mathrm{R}_{\mathrm{L}}$, calculated by:

$$
\mathrm{R}_{\mathrm{L}}=1 /\left(1+\mathrm{bC}_{0}\right)
$$

where $b$ is the Langmuir constant, and $C_{0}$ is the initial dye concentration $(m g / L) . R_{L}$ is a dimensionless separation factor used to determine whether the adsorption process is favorable or unfavorable. The shapes of the isotherms for $0<\mathrm{R}_{\mathrm{L}}<1, \mathrm{R}_{\mathrm{L}}>1, \mathrm{R}_{\mathrm{L}}=1$, and $\mathrm{R}_{\mathrm{L}}=0$ are favorable, unfavorable, linear, and irreversible [1], respectively.

The Freundlich isotherm [31] is given by the following equation:

$$
\mathrm{q}_{\mathrm{e}}=\mathrm{k}_{\mathrm{f}} \mathrm{C}^{1 / \mathrm{n}}
$$

where $\mathrm{k}_{\mathrm{f}}$ is the coefficient for the adsorbed amount, and $\mathrm{n}$ is the Freundlich constant.

The adsorption data were also found to fit the linear form of the Freundlich equation $\left(R^{2}=0.990\right)$ :

$$
\ln q_{e}=\ln k_{f}+(1 / n) \ln C_{e}
$$

The calculated parameters from the Langmuir and Freundlich isotherms for MB on MPPL at $30{ }^{\circ} \mathrm{C}$ are shown in Table 3. The $\mathrm{R}^{2}$ Langmuir value was 0.998 higher than the Freundlich value, thus indicating that the adsorption of MB on MPPL fitted the Langmuir model well. Furthermore, the RL of 0.23 was in the range of $0-1$, thus suggesting that the adsorption of MB on MPPL is favorable.

Table 3. Isotherm parameters for MB dye adsorption onto MPPL.

\begin{tabular}{cccccccc}
\hline \multirow{2}{*}{ Isotherms } & \multicolumn{3}{c}{ Langmuir Model } & \multicolumn{4}{c}{ Freundlich Model } \\
\cline { 2 - 8 } & $\mathbf{b}$ & $\mathbf{q} \mathbf{m}$ & $\mathbf{R}^{\mathbf{2}}$ & $\mathbf{R}_{\mathbf{L}}$ & $\mathbf{k}_{\mathbf{f}}$ & $\mathbf{1 / n}$ & $\mathbf{R}^{\mathbf{2}}$ \\
\hline Parameters & 0.066 & 104.17 & 0.998 & 0.233 & 3.289 & 1.708 & 0.990 \\
\hline
\end{tabular}

\subsection{Thermodynamic Study}

The adsorption capacity of MB at equilibrium at $303 \mathrm{~K}, 313 \mathrm{~K}$, and $323 \mathrm{~K}$ was used to obtain thermodynamic parameters [32]. Changes in standard enthalpy $\left(\Delta \mathrm{H}^{\circ}\right)$, standard entropy $\left(\Delta \mathrm{S}^{\circ}\right)$, and standard Gibbs free energy $\left(\Delta G^{\circ}\right)$ were calculated according to the following equations:

$$
\begin{gathered}
\Delta G^{\circ}=-R T \ln K_{d} \\
K_{d}=q_{e} / C_{e} \\
\ln K_{d}=-\Delta H^{\circ} / R T+\Delta S^{\circ} / R
\end{gathered}
$$

where $\mathrm{R}$ is the universal gas constant $\left(8.314 \mathrm{~J} \mathrm{~K}^{-1} \mathrm{~mol}^{-1}\right)$, and $\mathrm{K}_{\mathrm{d}}$ is the equilibrium constant for the adsorption at standard temperature and pressure.

As shown in Table 4 , the $\Delta G^{\circ}$ values were negative, thus indicating that the adsorption of methylene blue dye on MPPL was a spontaneous and favorable process under the experimental conditions. $\Delta S^{\circ}$ was positive, thus indicating increased randomness at the interface of MPPL/MB solution during the adsorption process. The negative $\Delta \mathrm{H}^{\circ}$ indicated that the adsorption process was exothermic, and increasing the temperature would not favor the adsorption of MB on MPPL. In addition, an increase in $\Delta \mathrm{G}^{\circ}$ value with increasing temperature confirmed that the adsorption of MB on MPPL was more favorable at lower temperature. 
Table 4. Thermodynamic parameters for MB adsorption onto PPL and MPPL.

\begin{tabular}{ccccc}
\hline \multirow{2}{*}{$\boldsymbol{\Delta} \mathbf{H}^{\circ}\left(\mathbf{k J ~ m o l}^{-\mathbf{1}}\right)$} & \multirow{2}{*}{$\mathbf{S}^{\circ}\left(\mathbf{J ~ m o l}^{-1} \mathbf{K}^{-\mathbf{1}}\right)$} & \multicolumn{3}{c}{$\left.\Delta \mathbf{G}^{\circ} \mathbf{( k J ~ m o l}{ }^{-\mathbf{1}}\right)$} \\
\cline { 3 - 5 } & & $\mathbf{3 0 3} \mathbf{K}$ & $\mathbf{3 1 4} \mathbf{K}$ & $\mathbf{3 2 4 . 5} \mathbf{K}$ \\
\hline-27.91 & -64.70 & -8.30 & -7.59 & -6.91 \\
\hline
\end{tabular}

\section{Materials and Methods}

\subsection{Materials}

PPL was collected from a local market as solid waste. Citric acid (CA, $\left.\mathrm{C}_{6} \mathrm{H}_{8} \mathrm{O}_{7} \bullet \mathrm{H}_{2} \mathrm{O}\right)$ purchased from Kemiou Chemical Reagent Co., Ltd. (Tianjin, China) was used as a modification agent for the preparation of adsorbent. $\mathrm{MB}\left(\mathrm{C}_{16} \mathrm{H}_{18} \mathrm{ClN}_{3} \mathrm{~S}\right)$ was supplied by Aladdin Chemistry Co. Ltd. (Shanghai, China). All other chemicals and reagents were of analytical grade and were used without further purification.

\subsection{Preparation of Adsorbents}

The yellow skin was removed from pomelo peel, and the white soft and spongy part was obtained and washed several times with distilled water, then air-dried to a constant weight. The pretreated PPL was boiled in distilled water for $1 \mathrm{~h}$ to remove some soluble components and then dried at $60^{\circ} \mathrm{C}$. Finally, the dry PPL was ground into small particles (60-80 mesh size).

The procedure of the dehydration reaction of citric acid and its reaction with cellulose has been reported [33]. Citric acid first forms a five-membered cyclic anhydride intermediate at elevated temperatures by the dehydration of two adjacent carboxyl groups. The anhydride intermediate then reacts with cellulosic hydroxyl to form an ester linkage. To prepare MPPL, PPL powder (5 g) and $150 \mathrm{~mL}$ of $0.6 \mathrm{~mol} \mathrm{~L}^{-1}$ citric acid solution were added to a beaker and stirred at room temperature; the mixture was dried at $55^{\circ} \mathrm{C}$ for $20 \mathrm{~h}$ and then heated to $120^{\circ} \mathrm{C}$ for $90 \mathrm{~min}$. After cooling, the residue was filtered and then immersed into the $0.1 \mathrm{~mol} \mathrm{~L}^{-1}$ of $\mathrm{NaOH}$ solution $(100 \mathrm{~mL})$ for $1 \mathrm{~h}$. Finally, the sample was washed with hot water at $70{ }^{\circ} \mathrm{C}$ and dried in an oven at $60^{\circ} \mathrm{C}$ for $24 \mathrm{~h}$. A schematic diagram for MPPL preparation is shown in Figure 8.

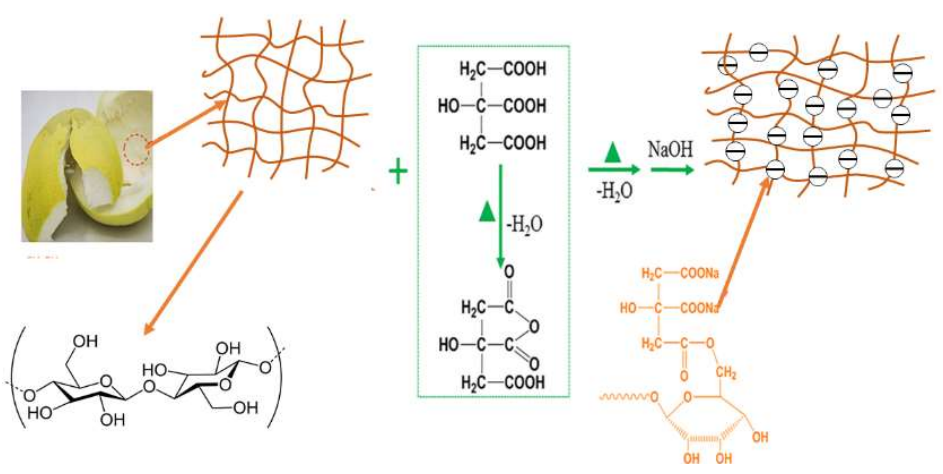

Figure 8. Schematic diagram for the MPPL preparation.

\subsection{Characterization}

FTIR spectra were recorded by a TENSOR27 instrument, using the attenuated total reflectance method [34]. The samples were loaded into a KBr disk, followed by extruding the material with $8 \mathrm{MT}$ pressure bench press. The FTIR spectrum was measured in the wavenumber of 4000 to $500 \mathrm{~cm}^{-1}$ at $4 \mathrm{~cm}^{-1}$ resolution. Scanning electron microscopy (SEM) (Model Hitachi S-3000N) was applied to observe the morphology of the adsorbent at an electron acceleration voltage of $20 \mathrm{kV}$. Before measurement, the samples were coated with a sputter coater to make them conductive [35]. The point 
of zero charge $\left(\mathrm{pH}_{\mathrm{PZC}}\right)$ of the adsorbent was determined between $\mathrm{pH} 2.5$ to 11 . Then, the initial and final $\mathrm{pH}$ of the adsorbent dispersions after storage for $240 \mathrm{~min}$ were recorded.

\subsection{Batch Experiments}

Batch experiments were performed to evaluate the performance of the adsorbent in removing MB from aqueous solution [34,35]. In each adsorption experiment, a certain amount of adsorbent and $50 \mathrm{~mL}$ of MB solution were mixed into a $250 \mathrm{~mL}$ of beaker flask and shaken at $100 \mathrm{rpm}$. The effects of the initial $\mathrm{MB}$ concentration, contact time and $\mathrm{pH}$ on the adsorption performance were examined. The $\mathrm{pH}$ of the initial MB solution was adjusted with $0.1 \mathrm{~mol} \mathrm{~L}^{-1}$ of $\mathrm{NaOH}$ solution and $0.1 \mathrm{~mol} \mathrm{~L}^{-1}$ of $\mathrm{HCl}$ solution in the range of 2 to 10, as monitored with a $\mathrm{pH}$ meter. After adsorption, the mixture was filtered to remove the adsorbents, and the residual MB solution was measured with a visible spectrophotometer at $\lambda_{\max }=665 \mathrm{~nm}$. The standard curve of MB is expressed by the following equation:

$$
\mathrm{Y}=0.1705 \mathrm{X}+0.01506, \mathrm{R}^{2}=0.9984
$$

The removal rate $(\mathrm{R}, \%)$ and the adsorption capacity $\left(\mathrm{q}, \mathrm{mg} \mathrm{g}^{-1}\right)$ were calculated using the following equations:

$$
\begin{gathered}
\mathrm{R}=\left(\mathrm{C}_{0}-\mathrm{C}_{\mathrm{t}}\right) / \mathrm{C}_{0} \times 100 \% \\
\mathrm{q}=\left(\mathrm{C}_{0}-\mathrm{C}_{\mathrm{e}}\right) \times \mathrm{V}_{0} / \mathrm{m}
\end{gathered}
$$

where $C_{0}, C_{e}$ and $C_{t}\left(\mathrm{mg} \mathrm{L}^{-1}\right)$ are the $\mathrm{MB}$ concentration of the residual solution in the initial solution, at equilibrium and at time $t$, respectively. $V_{0}$ is the volume of $M B$ solution, and $m$ is the mass of the adsorbent.

\section{Conclusions}

In this study, a PPL-based bio-sorbent was prepared through a simple heat esterification method. FTIR analysis revealed that carboxylic anions were successfully introduced to PPL after modification with citrate. The SEM micrographs showed that the modification did not destroy the initial porous structure of PPL. The modification significantly improved the adsorption of MB. The adsorption of MB on MPPL initially increased quickly and reached equilibrium at $3 \mathrm{~h}$. Kinetic analysis indicated that the adsorption was well described by a pseudo-second order model. The adsorption process was well fitted by the Langmuir model, and the predicted maximum adsorption capacity was $104.17 \mathrm{mg} / \mathrm{g}$. The negative values of $\Delta \mathrm{G}^{\circ}, \Delta \mathrm{H}^{\circ}$, and $\Delta \mathrm{S}^{\circ}$ calculated from the thermodynamic equations indicated that the adsorption of MB on MPPL was spontaneous and exothermic and was an entropy decreasing process. Because of the abundance and wide availability of PPL, and its ease of modification, MPPL may be a potential adsorbent for purification of wastewater containing cationic pollutants.

Author Contributions: Conceptualization, Y.R., C.C. and P.W.; Methodology, Y.R.; Software, Y.R.; Validation, Y.R.; Formal Analysis, Y.R.; Data Curation, C.C.; Writing-Original Draft Preparation, Y.R.; Writing-Review \& Editing, Y.R.; Supervision, P.W.; Project Administration, P.W.; Funding Acquisition, P.W.

Funding: This research was funded by Project funded by China Postdoctoral Science Foundation, and also supported by the Open Project Program of Beijing Key Laboratory of Flavor Chemistry, Beijing Technology and Business University (BTBU), Beijing 100048, China.

Conflicts of Interest: The authors declare no conflict of interest.

\section{References}

1. Lim, L.B.L.; Priyantha, N.; Tennakoon, D.T.B.; Chieng, H.I.; Dahri, M.K.; Suklueng, M. Breadnut peel as a highly effective low-cost biosorbent for methylene blue: Equilibrium, thermodynamic and kinetic studies. Arab. J. Chem. 2017, 10, S3216-S3228. [CrossRef] 
2. Mouni, L.; Belkhiri, L.; Bollinger, J.-C.; Bouzaza, A.; Assadi, A.; Tirri, A.; Dahmoune, F.; Madani, K.; Remini, H. Removal of Methylene Blue from aqueous solutions by adsorption on Kaolin: Kinetic and equilibrium studies. Appl. Clay Sci. 2018, 153, 38-45. [CrossRef]

3. Carvalho, J.; Araujo, J.; Castro, F. Alternative Low-cost Adsorbent for Water and Wastewater Decontamination Derived from Eggshell Waste: An Overview. Waste Biomass Valoriz. 2011, 2, 157-167. [CrossRef]

4. Dahri, M.K.; Kooh, M.R.R.; Lim, L.B.L. Water remediation using low cost adsorbent walnut shell for removal of malachite green: Equilibrium, kinetics, thermodynamic and regeneration studies. J. Environ. Chem. Eng. 2014, 2, 1434-1444. [CrossRef]

5. Gupta, N.; Kushwaha, A.K.; Chattopadhyaya, M.C. Application of potato (Solanum tuberosum) plant wastes for the removal of methylene blue and malachite green dye from aqueous solution. Arab. J. Chem. 2016, 9 , S707-S716. [CrossRef]

6. Bhatnagar, A.; Sillanpää, M.; Witek-Krowiak, A. Agricultural waste peels as versatile biomass for water purification-A review. Chem. Eng. J. 2015, 270, 244-271. [CrossRef]

7. Lim, L.B.L.; Priyantha, N.; Mansor, N.H.M. Artocarpus altilis (breadfruit) skin as a potential low-cost biosorbent for the removal of crystal violet dye: Equilibrium, thermodynamics and kinetics studies. Environ. Earth Sci. 2015, 73, 3239-3247. [CrossRef]

8. Suemitsu, R.; Uenishi, R.; Akashi, I.; Nakano, M. The use of dyestuff-treated rice hulls for removal of heavy metals from waste water. J. Appl. Polym. Sci. 1986, 31, 75-83. [CrossRef]

9. Kowalik, P.J.; Randerson, P.F. Nitrogen and phosphorus removal by willow stands irrigated with municipal waste water-A review of the Polish experience. Biomass Bioenerg 1994, 6, 133-139. [CrossRef]

10. Periasamy, K.; Namasivayam, C. Removal of copper(II) by adsorption onto peanut hull carbon from water and copper plating industry wastewater. Chemosphere 1996, 32, 769-789. [CrossRef]

11. Amin, M.N.; Mustafa, A.I.; Khalil, M.I.; Rahman, M.; Nahid, I. Adsorption of phenol onto rice straw biowaste for water purification. Clean Technol. Environ. Policy 2012, 14, 837-844. [CrossRef]

12. Taha, G.M. Utilization of Low-Cost Waste Material Bagasse Fly Ash in Removing of $\mathrm{Cu}^{2+}, \mathrm{Ni}^{2+}, \mathrm{Zn}^{2+}$, and $\mathrm{Cr}^{3+}$ from Industrial Waste Water. Groundw. Monit. 2006, 26, 137-141. [CrossRef]

13. Pacaphol, K.; Aht-Ong, D. Preparation of hemp nanofibers from agricultural waste by mechanical defibrillation in water. J. Clean. Prod. 2017, 142, 1283-1295. [CrossRef]

14. Khaskheli, M.I.; Memon, S.Q.; Siyal, A.N.; Khuhawar, M.Y. Use of Orange Peel Waste for Arsenic Remediation of Drinking Water. Waste Biomass Valoriz. 2011, 2, 423-433. [CrossRef]

15. Adel, A.M.; Abd El-Wahab, Z.H.; Ibrahim, A.A.; Al-Shemy, M.T. Characterization of microcrystalline cellulose prepared from lignocellulosic materials. Part II: Physicochemical properties. Carbohydr. Polym. 2011, 83, 676-687. [CrossRef]

16. Jong, M.-C.; Su, J.-Q.; Bunce, J.T.; Harwood, C.R.; Snape, J.R.; Zhu, Y.-G.; Graham, D.W. Co-Optimization of sponge-core bioreactors for removing total nitrogen and antibiotic resistance genes from domestic wastewater. Sci. Total Environ. 2018, 634, 1417-1423. [CrossRef] [PubMed]

17. Tang, L.; Liu, Y.; Wang, J.; Zeng, G.; Deng, Y.; Dong, H.; Feng, H.; Wang, J.; Peng, B. Enhanced activation process of persulfate by mesoporous carbon for degradation of aqueous organic pollutants: Electron transfer mechanism. Appl. Catal. B Environ. 2018, 231, 1-10. [CrossRef]

18. Duan, P.; Xu, X.; Shang, Y.; Gao, B.; Li, F. Amine-crosslinked Shaddock Peel embedded with hydrous zirconium oxide nano-particles for selective phosphate removal in competitive condition. J. Taiwan Inst. Chem. E 2017, 80, 650-662. [CrossRef]

19. Chai, W.; Liu, X.; Zou, J.; Zhang, X.; Li, B.; Yin, T. Pomelo peel modified with acetic anhydride and styrene as new sorbents for removal of oil pollution. Carbohydr. Polym. 2015, 132, 245-251. [CrossRef] [PubMed]

20. Argun, M.E.; Güclü, D.; Karatas, M. Adsorption of Reactive Blue 114 dye by using a new adsorbent: Pomelo peel. J. Ind. Eng. Chem. 2014, 20, 1079-1084. [CrossRef]

21. Foo, K.Y.; Hameed, B.H. Microwave assisted preparation of activated carbon from pomelo skin for the removal of anionic and cationic dyes. Chem. Eng. J. 2011, 173, 385-390. [CrossRef]

22. Li, F.; Tang, Y.; Wang, H.; Yang, J.; Li, S.; Liu, J.; Tu, H.; Liao, J.; Yang, Y.; Liu, N. Functionalized hydrothermal carbon derived from waste pomelo peel as solid-phase extractant for the removal of uranyl from aqueous solution. Environ. Sci. Pollut. Res. Int. 2017, 24, 22321-22331. [CrossRef] [PubMed] 
23. Wu, Y.; Cha, L.; Fan, Y.; Fang, P.; Ming, Z.; Sha, H. Activated Biochar Prepared by Pomelo Peel Using H3PO4 for the Adsorption of Hexavalent Chromium: Performance and Mechanism. Water Air Soil Pollut. 2017, 228, 405. [CrossRef]

24. Hameed, B.H.; Mahmoud, D.K.; Ahmad, A.L. Sorption of basic dye from aqueous solution by pomelo (Citrus grandis) peel in a batch system. Colloids Surf. Physicochem. Eng. Aspects 2008, 316, 78-84. [CrossRef]

25. Widsten, P.; Dooley, N.; Parr, R.; Capricho, J.; Suckling, I. Citric acid crosslinking of paper products for improved high-humidity performance. Carbohydr. Polym. 2014, 101, 998-1004. [CrossRef] [PubMed]

26. Ortiz, R.; Márquez, O.P.; Márquez, J.; Gutiérrez, C. FTIR spectroscopy study of the electrochemical reduction of $\mathrm{CO}_{2}$ on various metal electrodes in methanol. J. Electroanal. Chem. 1995, 390, 99-107. [CrossRef]

27. Ghosh, S.K.; Bandyopadhyay, A. Adsorption of methylene blue onto citric acid treated carbonized bamboo leaves powder: Equilibrium, kinetics, thermodynamics analyses. J. Mol. Liq. 2017, 248, 413-424. [CrossRef]

28. Chen, L.; Li, Y.; Du, Q.; Wang, Z.; Xia, Y.; Yedinak, E.; Lou, J.; Ci, L. High performance agar/graphene oxide composite aerogel for methylene blue removal. Carbohydr. Polym. 2017, 155, 345-353. [CrossRef] [PubMed]

29. Vasanth Kumar, K.; Sivanesan, S. Isotherms for Malachite Green onto rubber wood (Hevea brasiliensis) sawdust: Comparison of linear and non-linear methods. Dyes Pigment. 2007, 72, 124-129. [CrossRef]

30. Li, Y.; Gao, B.; Wu, T.; Wang, B.; Li, X. Adsorption properties of aluminum magnesium mixed hydroxide for the model anionic dye Reactive Brilliant Red K-2BP. J. Hazard. Mater. 2009, 164, 1098-1104. [CrossRef] [PubMed]

31. Freundlich, H.M.F. Over the adsorption in solution. J. Phys. Chem. 1906, 57, 385-470.

32. Buvaneswari, N.; Kannan, C. Plant toxic and non-toxic nature of organic dyes through adsorption mechanism on cellulose surface. J. Hazard. Mater. 2011, 189, 294-300. [CrossRef] [PubMed]

33. Yang, C.Q.; Wang, X.; Kang, I.-S. Ester Crosslinking of Cotton Fabric by Polymeric Carboxylic Acids and Citric Acid. Text. Res. J. 1997, 67, 334-342. [CrossRef]

34. Chowdhury, S.; Saha, P. Sea shell powder as a new adsorbent to remove Basic Green 4 (Malachite Green) from aqueous solutions: Equilibrium, kinetic and thermodynamic studies. Chem. Eng. J. 2010, 164, 168-177. [CrossRef]

35. Chowdhury, S.; Mishra, R.; Saha, P.; Kushwaha, P. Adsorption thermodynamics, kinetics and isosteric heat of adsorption of malachite green onto chemically modified rice husk. Desalination 2011, 265, 159-168. [CrossRef]

Sample Availability: Samples of the modified pomelo peels are available from the authors.

(C) 2018 by the authors. Licensee MDPI, Basel, Switzerland. This article is an open access article distributed under the terms and conditions of the Creative Commons Attribution (CC BY) license (http:/ / creativecommons.org/licenses/by/4.0/). 